\title{
Role of Non-Culture-Based Tests, with an Emphasis on Galactomannan Testing for the Diagnosis of Invasive Aspergillosis
}

\author{
Marisa H. Miceli, $\mathrm{MD}^{1}$ Johan Maertens, MD, $\mathrm{PhD}^{2}$ \\ ${ }^{1}$ Division of Infectious Diseases, Department of Internal Medicine, \\ University of Michigan Medical School, Ann Arbor, Michigan \\ 2 Acute Leukemia and Stem Cell Transplantation Unit, Universitaire \\ Ziekenhuizen Leuven, Campus Gasthuisberg, Catholic University, \\ Leuven, Belgium
}

Semin Respir Crit Care Med 2015;36:650-661.

\author{
Address for correspondence Marisa H. Miceli, MD, Division of \\ Infectious Diseases, Department of Internal Medicine, University of \\ Michigan Medical School, 1500 E. Medical Center Drive, Ann Arbor, MI \\ 48105 (e-mail: mmiceli@med.umich.edu).
}

\begin{abstract}
Keywords

- galactomannan

- beta-D-glucan

- polymerase chain reaction

- Aspergillus

- diagnosis

- preemptive

An established diagnosis of invasive aspergillus is seldom achieved premortem. Conventional laboratory diagnostic methods such as culture and microscopy, although very useful when positive, are insensitive and time-consuming, resulting in late diagnosis and treatment and contributing to high mortality rates. As a result, routine antifungal prophylaxis and early empirical treatment have been recommended. The use of sensitive and rapid non-culture-based diagnostic assays for the detection of Aspergillus antigens (using commercially available tests to detect galactomannan and 1, $3 \beta$-Dglucan) or detection of genomic DNA sequences may allow a shift in emphasis from empirical to preemptive therapy, especially when substantiated by suggestive radiological findings. These new tools may be used to confirm a presumed diagnosis of invasive aspergillosis, or, when used to screen high-risk patients, may identify an infection at an early stage of disease. Their excellent negative predictive value should convince clinicians to withhold antifungal therapy in patients with no other signs of fungal disease. On the other hand, consecutive positive results should at least trigger a complete diagnostic workup. This article will review the diagnostic utility as well as the pitfalls of using these non-culture-based tools for diagnosing invasive aspergillosis.
\end{abstract}

Invasive aspergillosis remains a major cause of morbidity and mortality in severely immunocompromised patients. ${ }^{1}$ Patients with profound and prolonged neutropenia are at increased risk of invasive aspergillosis. Thus, invasive aspergillosis is most frequent among patients with acute leukemia or high-risk myelodysplastic syndrome and allogeneic hematopoietic stem cell transplant (HCT) recipients. ${ }^{2}$ Other known risk factors for invasive aspergillosis include solidorgan transplantation (SOT) (particularly lung transplantation), chronic steroid use, and chemotherapy for solid tumors. ${ }^{3}$ However, the epidemiology of invasive fungal infections is changing and the spectrum of patients at risk for invasive aspergillosis has expanded beyond these "classic" host factors to include patients in the intensive care unit (ICU) (in particular patients with liver cirrhosis), burn and trauma unit. $^{4}$

Timely diagnosis and prompt initiation of antifungal therapy have a profound impact on the outcome of patients with invasive aspergillosis. ${ }^{5,6}$ However, the diagnosis of invasive aspergillosis is not easy, mainly due to the lack of a single gold standard test. The diagnosis of invasive aspergillosis is based on host factors and clinical, radiologic, and microbiologic criteria, which are neither sensitive nor specific. ${ }^{3}$ Typically, a definitive diagnosis of invasive aspergillosis requires an invasive procedure to establish a microbiological diagnosis by isolating the organism from a normally sterile site and/or
Issue Theme Pulmonary and Invasive Fungal Infections; Guest Editor: Carol A. Kauffman, MD
Copyright @ 2015 by Thieme Medical Publishers, Inc., 333 Seventh Avenue, New York, NY 10001, USA. Tel: +1(212) 584-4662.
DOI http://dx.doi.org/ 10.1055/s-0035-1562892. ISSN 1069-3424. 
evidence of tissue invasion on histopathology. These invasive procedures are often difficult to obtain in critically ill patients. Consequently, a definite diagnosis of invasive aspergillosis is rarely established in early stages of the infection and delayed initiation of appropriate antifungal therapy is not uncommon. $5,7,8$

Non-culture-based diagnostic assays (i.e., galactomannan [GM] and 1,3 $\beta$-D-glucan [BDG], PCR-based DNA detection tests) for the diagnosis of invasive fungal diseases have been developed over the last two decades. These indirect tests represent a major advance for the management of patients at risk for invasive fungal disease. Indeed, the availability of these surrogate markers has been critical to develop new strategies focused on early diagnosis and prompt initiation of therapy (-Fig. 1). ${ }^{9,10}$

\section{EORTC/MSG Definitions}

Current definitions used for the diagnosis of invasive fungal disease were initially developed by the European Organization for Research and Treatment of Cancer/Invasive Fungal Infections Cooperative Group (EORTC) and the National Institute of Allergy and Infectious Diseases Mycoses Study Group (MSG). The main purpose of these definitions was to facilitate research studies by unifying the diagnostic criteria of invasive fungal disease, including invasive aspergillosis. ${ }^{11}$ These definitions are based on the level of probability to the diagnosis of invasive fungal infection occurring mostly in immunocompromised patients. ${ }^{11}$ Classically, invasive fungal diseases have been divided in three categories: "proven," "probable," and "possible" based on host factors, clinical and radiological presentation, as well as mycological evidence. In 2008, these definitions were revised and modified to reflect the advances in diagnosis; indirect tests were included as part of the microbiological criteria to provide more accurate and homogeneous diagnostic criteria of invasive fungal disease. ${ }^{3}$ In clinical practice, medical imaging and noninvasive diagnostic tests (i.e., GM and BDG) have become the most common tools used for the diagnosis of invasive aspergillosis.

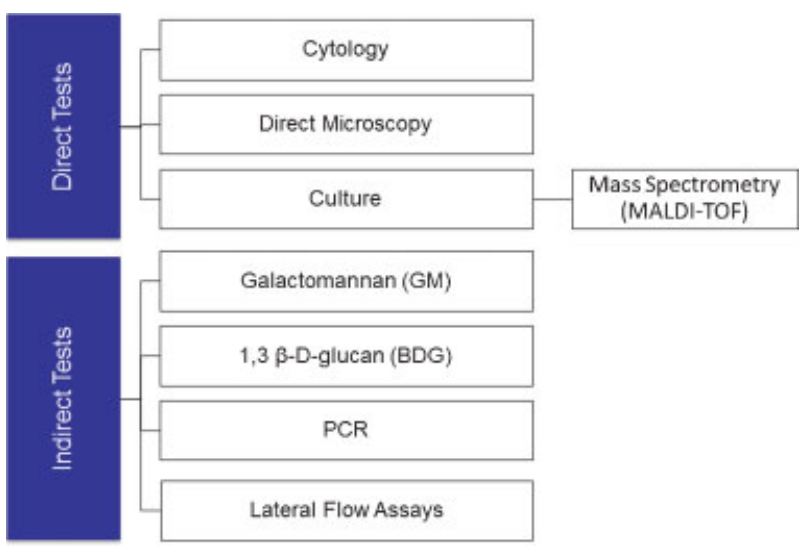

Fig. 1 Methods used for the detection of invasive aspergillosis.

\section{Non-culture-based methods for the diagnosis of Invasive Aspergillosis}

The lack of efficient diagnostic tools has led to the development of surrogate markers for the diagnosis of invasive aspergillosis. These tests are based on the detection of fungal cell wall components and Aspergillus DNA in clinical samples. $^{12}$

The fungal cell wall is almost exclusively composed of polysaccharides. The main characteristic of this cell wall is that it plays an important role during active infection and serves as a reservoir of nutrients and enzymes that are essential for fungal growth. ${ }^{10} \mathrm{GM}$ is a polysaccharide present in the cell wall of Aspergillus species. The GM molecule is composed of mannose residues with side chains of $\beta-(1-5)-$ linked galactofuranosyl units. During the initial phase of logarithmic fungal growth, GM is incorporated into the cell wall. As apical growth continues, the hyphal tip becomes weaker and releases GM. ${ }^{13}$ Using an invitro model of the human alveolus, Hope et al correlated the kinetic profile of GM with the cellular events during Aspergillus invasion. This study demonstrated that levels of GM are closely related to the dynamics of angioinvasion. On the basis of their results, the authors proposed that GM is not released into the circulation until the fungus invades the endothelial compartment. $^{14}$

In addition, experimental animal models and autopsy series have revealed important differences in the pathology of aspergillosis between glucocorticoid-treated and neutropenic patients. Although the infection in neutropenic hosts is characterized by extensive angio-invasion, hemorrhagic thrombosis and necrosis, and a high fungal burden, glucocorticoid-immunosuppressed hosts usually present with extensive necrosis, less angio-invasion, and a much lower fungal burden. The latter is suggestive of an inflammation-driven disease. ${ }^{15,16}$ These pathobiological differences have important implications on the amount of circulating GM (high in neutropenic and low in steroid-suppressed patients), and hence on the performance of tests used for the detection of circulating GM.

The Platelia Aspergillus sandwich enzyme immunoassay (EIA) is used for the detection of GM. This test uses EB-A2, a monoclonal antibody derived from rats, which specifically binds to four galactofuranosyl residues of the GM molecule. ${ }^{17}$ With the presence of antigen in the specimen, a monoclonal antibody-GM-monoclonal antibody complex is formed. A chromogenic substrate is added to reveal the presence of such complexes by turning blue. Microplates are read using an optical reader that calculates the ratio of the optical density (OD) relative to a control provided by the manufacture (OD index [ODI]). Results of the assay are reported as ODI (-Fig. 2).

In the United States, the GM assay has recently been approved as a biomarker for clinical research by the Food and Drug Administration (FDA), though restricted to patients with hematologic malignancies or recipients of stem cell transplants. ${ }^{18-20}$ A positive serum result should be based on a cutoff GM index $\geq 0.5$ based on testing of two separate serum samples or a single sample with a value of $\geq 1.0$. A 

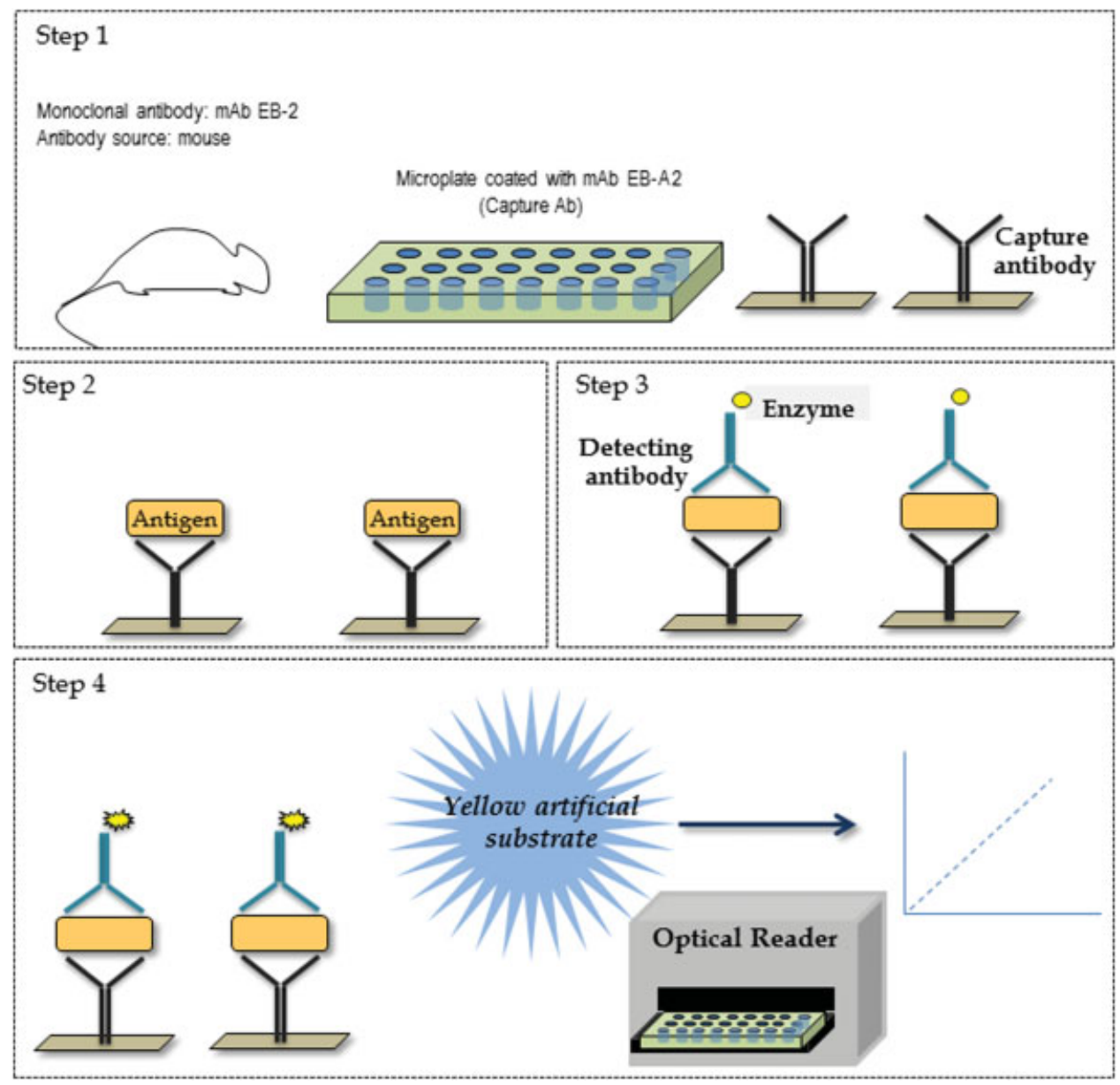

Fig. 2 Schematic representation of Aspergillus galactomannan ELISA immunoassay procedure. Step 1: Microplate wells are coated with murine monoclonal antibody (mAb) EB-A2 (capture antibody). Step 2: Treated serum or bronchoalveolar lavage sample is added to the wells. Step 3: Labeled anti-mAb EB-A2 antibody (detecting antibody) is added to the wells. In the presence of the antigen (EB-A2) a "mAb-antigen-labeled antimAb complex" is formed. Step 4: Substrate solution is added to the wells and the presence of "mAb-antigen-labeled anti-mAb complex" is revealed by forming a blue color. An optical reader is then used to calculate the optical density index (i.e., galactomannan test result).

positive result on bronchoalveolar lavage (BAL) fluid should be based on a cutoff GM index $\geq 1.0$ based on testing of two aliquots of a single BAL fluid sample. Of note, the EORTC-MSG revised consensus document has not specified cutoffs for positivity, but refers to the manufacturer's instructions.

The role of serum and BAL-GM for the diagnosis of invasive aspergillosis has been best established in patients with hematologic malignancies. ${ }^{10}$ Conversely, the role of these biomarkers in other patients at risk for invasive aspergillosis such as SOT recipients has not been established mainly because of the significant variation in performance observed in these patients. ${ }^{21,22}$ Although fairly specific for Aspergillus species, GM is also present in the cell wall of Penicillium, Fusarium, Alternaria, Acremonium, and Histoplasma capsulatum. ${ }^{23-25}$ Thus, cross-reactivity associated with these and other fungi has been reported. ${ }^{26}$ Galactofuranosyl residues are also present in other macromolecules that may crossreact with EB-A2 compromising assay performance (-Table 1). False-positive reactions have been reported in 1 to $18 \%$ of the tested samples and may be secondary to crossreactivity or false-positive GM due to other causes $(-$ Table 1$){ }^{27,28}$ In addition, factors such as cost and out- sourcing to reference laboratories limit testing frequency and timely availability of results.

Another polysaccharide present in the cell wall of Aspergillus spp. is BDG. Unlike GM, BDG is a component of the cell walls of many pathogenic fungi including Candida, Fusarium, and Pneumocystis. The main exceptions are Mucorales and Cryptococci, which release no or little BDG to be detected in human serum. ${ }^{29}$ BDG assays are commercially available. The Fungitell assay (Associates of Cape Cod, Inc., East Falmouth, MA, USA) is the most frequently used in Europe and North America. Fungitell detects BDG through a pathway in the Limulus amebocyte lysate (LAL), an aqueous extract of blood cells from the horseshoe crab, Limulus polyphemus. Bacterial endotoxins and BDG can activate different coagulation cascades in the LAL. For example, bacterial endotoxins specifically activate factors $B$ and $C$, while BDG activates factor $\mathrm{G}$. The Fungitell assay uses a modified pathway in the LAL, by removing factor $C$ from LAL. Thus, in the absence of factor $C$, the coagulation cascade is activated only by the presence of BDG. ${ }^{30}$ The activity of this reaction can be measured with the use of colorimetric method (-Fig. 3). The serum Fungitell assay was approved by the FDA in 2003 and carries the 
European CE marking for the presumptive diagnosis of invasive fungal disease. Overall, the BDG assay has a sensitivity of $77 \%$ and a specificity of $85 \%$ for the diagnosis of proven or probable IFI. ${ }^{31}$ Unfortunately, the BDG assay is not pathogen specific and therefore cannot differentiate fungal species. The major limitations of BDG testing for routine use are its low specificity and frequent occurrence of false-positive reactions. $^{32}$ Characteristic features and major limitations of BDG and GM assays are summarized in -Tables $\mathbf{1}$ and $\mathbf{2}$.

Three other kits for the detection of BDG, including the Fungitec-G test MK (Seikagaku Corporation, Tokyo, Japan), $\beta$-Glucan test Wako (Wako Pure Chemical Industries, Ltd., Osaka, Japan), and $\beta$-Glucan test Maruha (Maruha Nichiro Corporation, Tokyo, Japan), are currently used for diagnosis of invasive fungal diseases in Asia. Fungitell and the other three kits detect BGD through the activation of Factor $G$ of the LAL coagulation cascade (-Fig. 3). However, BGD measurement differs among these assays. Discrepancies in test performance and assay cutoffs among four kits may lead to erroneous interpretation of these tests and ultimately affect patient management. Thus, clinicians should be aware of the BDG kit used at each institution when interpreting results ( - Table 3$)^{33,34}$

Polymerase chain reaction (PCR)-based methods have also been developed for the diagnosis of invasive fungal disease. The main advantage of molecular detection of invasive as- pergillosis is the very high sensitivity for the detection of Aspergillus DNA. In addition, PCR-based methods could be applied to any specimen type. Indeed, PCR-based methods for Aspergillus DNA detection have been used in a variety of specimens including blood, serum, BAL fluid, cerebrospinal fluid (CSF), and tissue. ${ }^{17}$ Molecular methods using genus/ species-specific genes and panfungal targets have been developed for the detection of invasive fungal disease at the genus or species level. ${ }^{7,35}$ The usefulness of PCR and other molecular technology for the diagnosis of invasive fungal disease has been recently reviewed elsewhere. ${ }^{36,37}$ Superior performance compared with the currently available biomarkers has been suggested and reports are promising. However, the usefulness of PCR-based methods as a reliable tool for the diagnosis of invasive fungal diseases remains under investigation. Aspergillus PCR has therefore not (yet) been included in the 2008 EORTC-MSG consensus definitions.

Despite the advances in the field, the tools available for the diagnosis of invasive aspergillosis are far from perfect and clinicians still struggle to make a timely diagnosis. Therefore, the search for novel targets and platforms that may improve the diagnosis of invasive fungal diseases continues. ${ }^{38-41}$ Recently, Thornton has developed a novel lateral flow device (LFD) using an Aspergillus-specific monoclonal antibody. ${ }^{41}$ The LFD test for invasive aspergillosis detection enables the

Table 1 Major limitations of non-culture, non-molecular tests used for the diagnosis of Invasive Aspergillosis

\begin{tabular}{|c|c|c|c|}
\hline \multirow[t]{2}{*}{ Major caveats } & \multicolumn{3}{|c|}{ Non-molecular-based test } \\
\hline & 1,3 $\beta$-D-glucan (BDG) & Galactomannan (GM) & Lateral flow device (LFD) \\
\hline Cross-reactivity & $\begin{array}{l}\text { Pneumocystis jiroveci, Cocci- } \\
\text { dioides immitis, Fusarium sp., } \\
\text { Histoplasma capsulatum, Can- } \\
\text { dida sp., Acremonium, Tricho- } \\
\text { sporon sp., } \\
\text { Sporothrix schenckii, Saccha- } \\
\text { romyces cerevisiae, Aspergillus } \\
\text { sp. }\end{array}$ & $\begin{array}{l}\text { Aspergillus sp., Fusarium sp., } \\
\text { Paecilomyces sp., Penicillium sp., } \\
\text { Acremonium sp., Alternaria sp., } \\
\text { Wangiella dermatitidis, Histo- } \\
\text { plasma capsulatum, Blastomyces } \\
\text { dermatitidis, Cryptococcus neo- } \\
\text { formans, Emmonsia sp. }\end{array}$ & $\begin{array}{l}\text { Penicillium sp. Paecilomyces } \\
\text { variotii }\end{array}$ \\
\hline False positive results & $\begin{array}{l}\text { Semi-synthetic } \beta \text {-lactam anti- } \\
\text { biotics }^{\text {a }} \\
\text { Hemodialysis or hemofiltra- } \\
\text { tion with cellulose mem- } \\
\text { branes } \\
\text { Blood stream infectious with } \\
\text { bacteria (e.g.,Pseudomonas } \\
\text { aeruginosa) } \\
\text { Transfusions of blood or } \\
\text { blood-derived products } \\
\text { filtered through cellulose } \\
\text { membranes } \\
\text { Exposure to gauze (specifi- } \\
\text { cally packing of serosal } \\
\text { surfaces) } \\
\text { IV Immunoglobulin infusion } \\
\text { Albumin infusion }\end{array}$ & $\begin{array}{l}\text { Semi-synthetic } \beta \text {-lactam } \\
\text { antibiotics }^{\mathrm{a}} \\
\text { Severe mucositis or Severe gas- } \\
\text { trointestinal graft versus host } \\
\text { disease } \\
\text { Blood products collected using } \\
\text { Fresenius Kabi bags } \\
\text { Multiple myeloma (IgG type) } \\
\text { Plasmalyte used in BAL } \\
\text { Cotton swabs } \\
\text { Colonization (particularly in } \\
\text { lung transplant recipients) } \\
\text { Flavored ice-pops/frozen } \\
\text { desserts containing sodium } \\
\text { gluconate }\end{array}$ & Doxycycline \\
\hline False negative results & $\begin{array}{l}\text { Concomitant use of antifun- } \\
\text { gal prophylaxis or therapy }\end{array}$ & $\begin{array}{l}\text { Concomitant use of antifungal } \\
\text { prophylaxis or therapy }\end{array}$ & None reported \\
\hline
\end{tabular}

${ }^{a}$ Semisynthetic $\beta$-lactam antibiotics include ampicillin, amoxicillin-clavulanate, and piperacillin-tazobactam. False-positive results may persist for up to 5 days after discontinuation of these agents. 
Table 2 Characteristic features of non-culture, non-molecular tests used for the diagnosis of Invasive Aspergillosis

\begin{tabular}{|c|c|c|c|}
\hline \multirow[t]{2}{*}{ Test feature } & \multicolumn{3}{|c|}{ Non-molecular-based test } \\
\hline & BDG & GM & LFD \\
\hline Method & Biological cascade-based assay & $\begin{array}{l}\text { Anti-GM monoclonal anti- } \\
\text { body (mAb EB-A2) }\end{array}$ & $\begin{array}{l}\text { Anti-GM monoclonal } \\
\text { antibody (mAb JF-5) }\end{array}$ \\
\hline Commercial assay & Fungitell $^{\mathrm{a}}$ & Platelia Aspergillus EIA & Aspergillus LFD \\
\hline Result interpretation & $\begin{array}{l}\text { Negative result: }<60 \mathrm{pg} / \mathrm{mL} \\
\text { Intermediate result: } 60-79 \mathrm{pg} / \mathrm{mL} \\
\text { Positive result: } \geq 80 \mathrm{pg} / \mathrm{mL}\end{array}$ & $\begin{array}{l}\text { Negative result: }<0.5 \text { ODI } \\
\text { Positive result: } \geq 0.5 \text { ODI }\end{array}$ & $\begin{array}{l}\text { Qualitative method } \\
\text { (positive/negative } \\
\text { results) }\end{array}$ \\
\hline Clinical applications & Used for early detection of IFI & $\begin{array}{l}\text { Used for the early diagno- } \\
\text { sis of Invasive Aspergillosis } \\
\text { in adult patients }\end{array}$ & $\begin{array}{l}\text { Point-of-care testing for } \\
\text { early detection of Inva- } \\
\text { sive Aspergillosis }\end{array}$ \\
\hline FDA approval & Serum & Serum, BAL & Not approved \\
\hline CE approval & Serum & Serum, BAL & Serum, BAL \\
\hline $\begin{array}{l}\text { Test performance for the diag- } \\
\text { nosis of Invasive Aspergillosis }\end{array}$ & $\begin{array}{l}\text { Sensitivity: 77\% (67-84\%) } \\
\text { Specificity: 85\% (80-90\%) }\end{array}$ & $\begin{array}{l}\text { Serum-GM } \\
\text { Sensitivity: } 41-78 \% \\
\text { Specificity: } 60-95 \% \\
\text { BAL-GM }^{\mathrm{b}} \\
\text { Sensitivity: } 87 \%(79-92 \%) \\
\text { Specificity: } 89 \%(85-92 \%)\end{array}$ & $\begin{array}{l}\text { Serum-LFD' } \\
\text { Sensitivity: } 20-68 \% \\
\text { Specificity: } 72-98 \% \\
\text { BAL-LFD } \\
\text { Sensitivity: } 80-100 \% \\
\text { Specificity: } 81-95 \%\end{array}$ \\
\hline $\begin{array}{l}\text { Clinical significance in the diag- } \\
\text { nosis of Invasive Aspergillosis }\end{array}$ & Nonspecific for Aspergillus species & $\begin{array}{l}\text { Specific for Aspergillus } \\
\text { species }\end{array}$ & $\begin{array}{l}\text { Specific for Aspergillus } \\
\text { species }\end{array}$ \\
\hline
\end{tabular}

Abbreviations: BAL, bronchoalveolar lavage; BDG, 1,3 ß-D-glucan; GM, galactomannan; IFI, invasive fungal infection; LFD, lateral flow device; ODI, optic density index.

${ }^{a}$ Other kits used for the detection of BDG include Fungitec- G test MK (G-MK), beta-glucan test Wako (Curdlan), and the BGSTAR beta-glucan test Maruha which are available in Japan.

${ }^{b}$ Galactomannan test performance may vary depending on the patient population and cutoff point used. Table shows test performance using cutoff point 0.5 ODI.

cLateral flow test performance may vary depending on the patient population.

point-of-care diagnosis of invasive aspergillosis using a monoclonal antibody that is highly specific for growing Aspergillus species ( - Fig. 4). Compared with GM and BDG assays, the LFD test is quick, cheap, and does not require expensive equipment or specific laboratory capability to be run. The utility of the LFD in diagnosing invasive aspergillosis has been demonstrated in small studies using human serum and BAL fluid samples of patients (mainly SOT recipients) with invasive aspergillosis (-Tables 1 and 2). ${ }^{42-47}$ Further studies to determine the clinical usefulness of this test are currently underway.

\section{Galactomannan Performance}

\section{Serum or Plasma Galactomannan}

Serum or plasma is the most frequently tested specimen and appears to provide highest sensitivity (up to 100\% depending on the patient population and previous antifungal therapy). ${ }^{7}$ The performance of serum GM has been extensively examined in patients undergoing chemotherapy for acute leukemia or allogeneic HCT because of their increased risk for invasive aspergillosis. Overall, the best performance of serum GM has been observed in neutropenic high-risk patients using a cutoff of 0.5 ODI in two consecutive serum samples with a reported sensitivity and specificity up to 95 and $98 \%$, respectively. ${ }^{48}$
In 2006, Pfeiffer et al conducted a meta-analysis to evaluate the overall accuracy of serum GM for surveillance of invasive aspergillosis in high-risk population. ${ }^{22}$ In this systematic review, the authors analyzed 20 studies published between 1999 and 2005. Overall sensitivity and specificity of serum GM for proven invasive aspergillosis were $71 \%(95 \%$ confidence interval $[\mathrm{CI}], 0.68-74)$ and $89 \%$ (95\%Cl, 0.88-0.90), respectively. Proven invasive aspergillosis was defined according to the earliest version of EORCT/MSG criteria. ${ }^{3}$ The main limitations of this analysis were the significant heterogeneity among the patient populations studied (studies with bone marrow transplant recipients, 6; SOT recipients, 3; hematological malignancy patients, 17) and the different GM positivity cutoffs used in these studies (mainly 1.0 and $1.5)^{22}$

Similarly, Leeflang et al conducted a systematic review and meta-analysis of 30 studies evaluating the performance of serum GM for the diagnosis of proven or probable invasive aspergillosis in patients with neutropenia and/or impaired neutrophil function. ${ }^{49}$ The meta-analysis was stratified by the used GM cutoff $(0.5,1.0$, and $1.5 \mathrm{ODI})$. Seven of these 30 studies reported an overall sensitivity of $78 \%(61-89 \%)$ and mean specificity of $81 \%$ ( $72-88 \%$ ) using an ODI cutoff $>0.5$. For an ODI cutoff of 1.0 , overall sensitivity was $75 \%$ (59-86\%) and mean specificity was $91 \%$ (84-95\%). For studies using an ODI cutoff of 1.5 , sensitivity was $64 \%$ and specificity was $95 \%{ }^{49}$ 


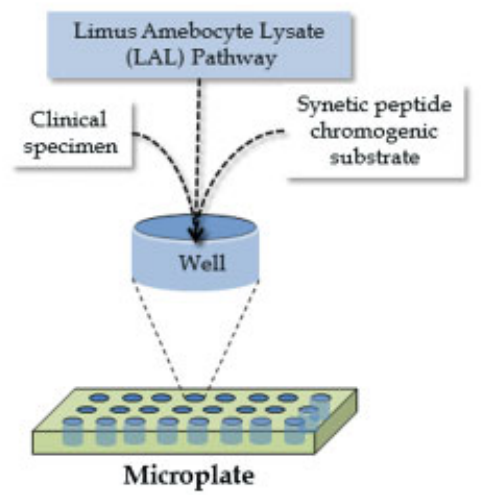

A
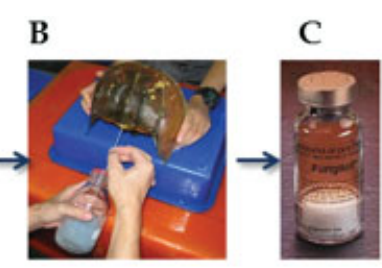

D

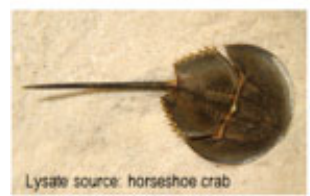

Lysab source horseshoe crab

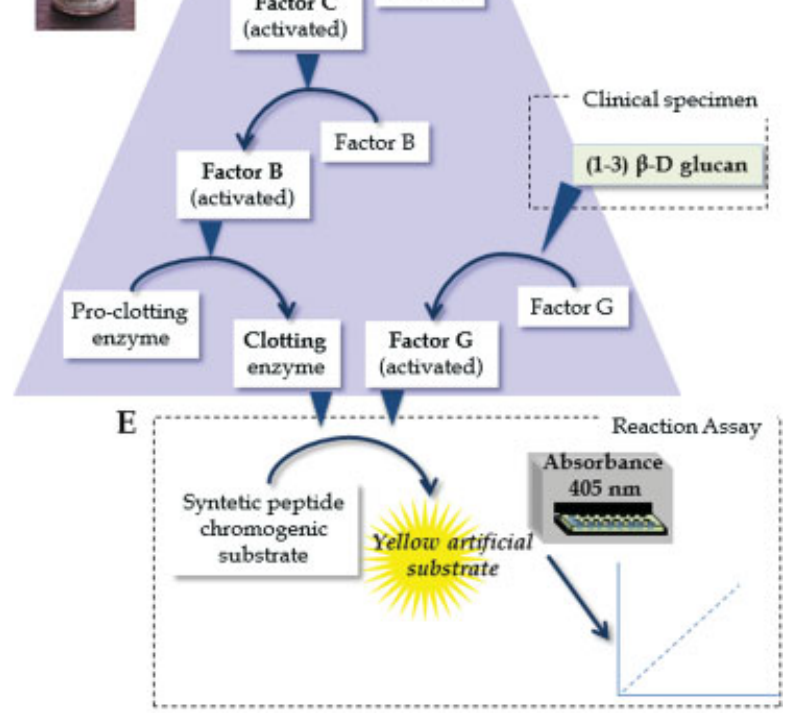

Fig. 3 Schematic representation of 1,3 $\beta$-D-glucan (BDG) assay procedure. (A) The horseshoe crab (Limulus polyphemus) is the source of lysate. (B) Hemolymph (blue) is removed from the horseshoe crabs' pericardium and then crabs are returned to the water. Hemolymph contains amebocytes (blood cells) packed with granules containing a clotting factor (coagulogen) that is essential for host defense and hemostasis. Hemolymph cells are separated from the serum using centrifugation and then lysed to obtain the coagulogen or "lysate" (i.e., Limulus amebocyte lysate[LAL]). (C) The lysate is purified and freeze-dried to form a white powder that then is packed and sold as BDG assay (e.g., Fungitell assay). (D) Modified Limulus amebocyte lysate pathway. (E) BDG assay is performed in microplates. After reagents are added, the microplates are read in an incubating reader (BDG test results).

Serum GM antigen has been shown to be a useful screening test for early diagnosis of invasive aspergillosis in patients at risk. ${ }^{22,50,51}$ Sulahian et al showed that GM can be detected in serum as early as 5 to 8 days before clinical signs develop (in $65.2 \%$ of patients), and findings on chest Xray are visible (in $71.5 \%$ of patients) and culture results become positive (in $100 \%$ of patients). ${ }^{7,51,52}$ These findings support the use of GM as a screening tool for patients at high risk of developing invasive aspergillosis (e.g., patients with hematologic malignancy treated with high-dose chemotherapy and HCT recipients). In this setting, the detection of positive results particularly in two consecutive serum samples provides strong support for the diagnosis of invasive aspergillosis. ${ }^{7}, 10,50$

\section{Galactomannan in Bronchoalveolar Lavage Fluid}

GM is a water-soluble molecule and therefore the test can be applied to specimens other than serum, including BAL fluid, CSF, pleural fluid, and urine. ${ }^{53}$ Performance of BAL-GM varies depending on the population tested and the cutoff point for positivity that is used. ${ }^{21}$ The BAL-GM is particularly helpful in nonneutropenic patients with pulmonary aspergillosis who typically will not have a positive serum GM result. Two recent meta-analyses have evaluated the performance of GM testing in BAL fluid. 21,54 Guo et al analyzed 13 studies and reported an overall sensitivity of $90 \%$ and specificity of $94 \%{ }^{54}$ Another meta-analysis and system review of 30 studies evaluated the role of BAL-GM for the diagnosis of proven or probable invasive aspergillosis. ${ }^{21}$ Overall, the test performance varied by patient population, cutoff value, and drug treatment. Thus, the pooled sensitivity and specificity were 87 and $89 \%$, respectively. Increasing the positivity cutoff value of BALGM did not impact sensitivity but resulted in an improved performance from 89 to $95 \%$ with an ODI cutoff $\geq 0.5$ and $\geq 1.0$, respectively. ${ }^{21}$ Fewer studies in this meta-analysis used higher cutoff values (i.e., 1.5, 2.0, and 2.5). However, increasing the ODI cutoff value did not appear to improve test performance. Indeed, the threshold for positive BAL-GM remains under debate owing to its great impact on test performance. For instance, in the United States, the BALGM assay has been approved by the FDA using a positivity cutoff value $\geq 0.5 \mathrm{ODI},{ }^{18,19}$ while most centers in Europe use a higher cutoff value (i.e., $>1.0$ ). ${ }^{18,20}$

Performance of BAL-GM is also affected by the technique used for BAL procedure, including the volume of instilled sterile saline during bronchoscopy as well as the volume and type of collected BAL fluid (i.e., alveolar vs. bronchial sample). ${ }^{55,56}$ Experts recommend the use of a standardized protocol for BAL testing. In addition, false-positive BAL-GM may also represent fungal colonization of the airway or contamination, which is not uncommon in lung transplant recipients and patients with chronic lung disease.

The use of mold-active prophylaxis or empiric therapy may also impact on the performance of BAL-GM. ${ }^{57}$ Variable 

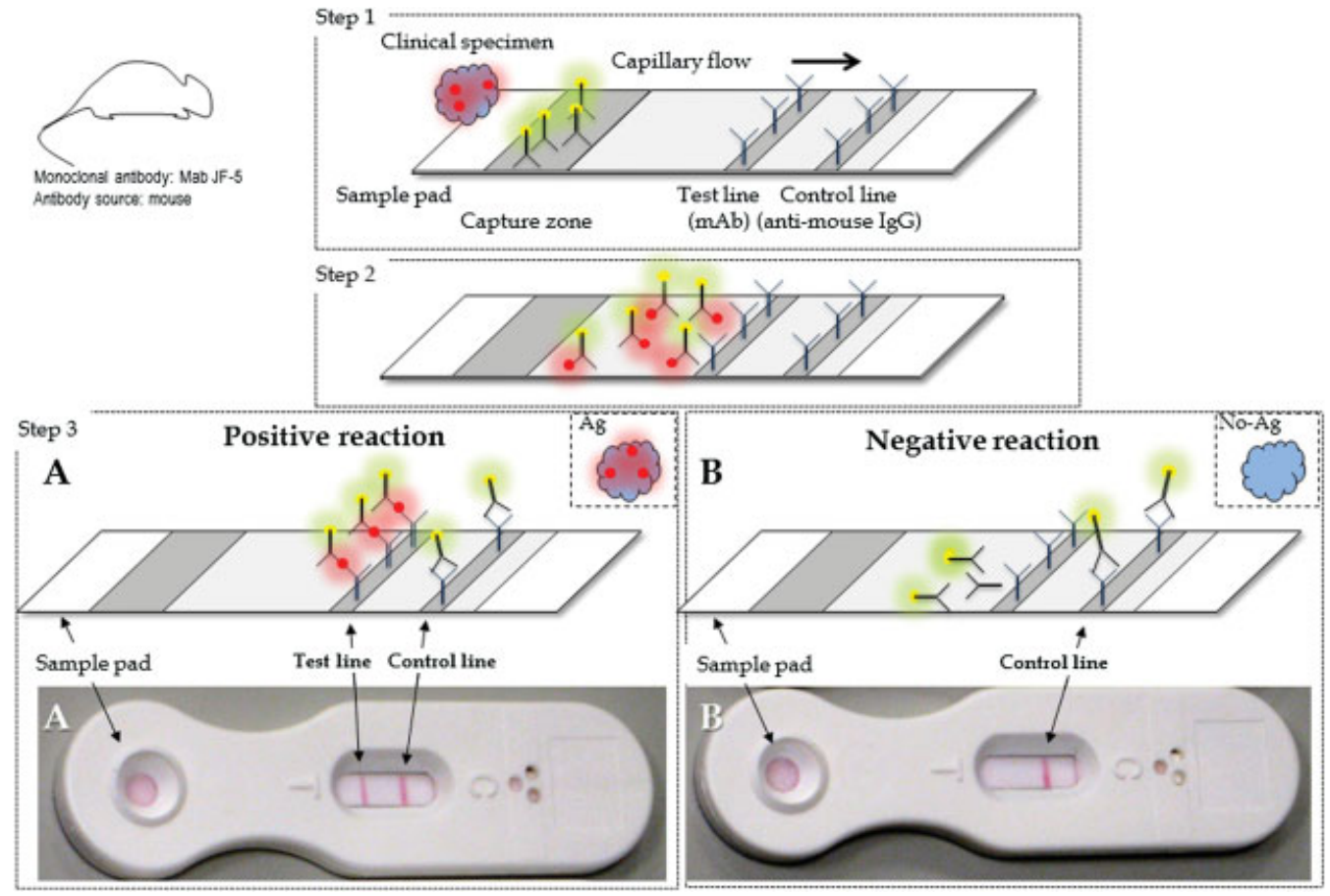

Fig. 4 Schematic representation of Aspergillus lateral flow device test procedure. Step 1: Monoclonal antibody JF5 (mAb JF5) is conjugated with gold particle that serves as a reagent. The mAb JF5-gold conjugate is immobilized in a capture zone of the release pad. Clinical specimen (i.e., serum or BAL) is added to the sample pad. Step 2: In the presence of target antigen (i.e., Ag JF5). The Ag JF5 will bind to the mAb JF5-gold conjugate in the capture zone. The MAb JF5-gold-Ag JF5 complex passes along the porous membrane via capillary flow. Step 3: (A) The mAb JF5gold-Ag JF5 complex binds the immobilized mAb JF5 in the test line (positive result). (B) Antimouse immunoglobulin (IgG) immobilized in the control line serves as a control line.

sensitivity of BAL-GM testing among patient receiving antimold active prophylaxis or empiric therapy has been reported and the data in the literature remain controversial. ${ }^{56}$ While some studies have shown no impact of antimold active prophylaxis or early empiric therapy, others report decreased sensitivity of BAL-GM if the patient has been on antifungal treatment for more than 3 days. ${ }^{58-60}$ On the other hand, increased sensitivities of BAL-GM have been reported among those patients just started on antimold active agents. ${ }^{61,62}$ On the basis of the current evidence, most authors advocate the use of BAL-GM as an adjunctive tool in the diagnosis of invasive aspergillosis.

\section{GM Detection in Other Specimens}

The use of the Platelia Aspergillus assay has extended to the testing of other biological samples besides serum and BAL fluid. GM can be detected in CSF in cases of invasive aspergillosis involving the central nervous system (CNS). ${ }^{63-65}$ Reportedly, CSF-GM indices of patients with probable CNS aspergillosis were statistically significantly higher than those of control patients with other neurological diseases (median CSF-GM 10.52 vs. 0.287 , respectively). ${ }^{63}$ The sensitivity and specificity were 80 and $100 \%$, respectively, in a study describing only five patients with proven CNS aspergillosis. ${ }^{64}$ Anecdotal evidence suggests that CSF-GM may result in earlier diagnosis of CNS invasive aspergillosis. As CSF-GM titers tend to decrease during effective therapy, serial testing has been suggested useful for monitoring response to treatment. ${ }^{63,65}$
Duettmann et al compared the performance of urine versus serum GM screening for early detection of invasive aspergillosis in 75 patients who had underlying hematological malignancies. ${ }^{66}$ In this study, GM positivity cutoff was 0.1 and 0.5 ODI for urine and serum specimens, respectively. Sensitivity, specificity, positive predictive value, and negative predictive value of urine GM were $47.6,86,24.4$, and $94.5 \%$, respectively. Correlation analysis revealed a significant positive correlation between serum and urine samples $(p<0.001 ; \rho=0.252){ }^{66}$

The detection of GM in cyst fluids from patients with polycystic kidney disease has been reported. ${ }^{67} \mathrm{GM}$ could also be detected in a subphrenic abscess of a pediatric patient with chronic granulomatous disease who had invasive aspergillosis. ${ }^{68}$ Finally, GM was detected in purulent material from patients with fungal rhinosinusitis. ${ }^{53}$ Although these are promising reports, the evidence to support the use of specimens other than blood and BAL for the detection of GM is limited..$^{53}$ Thus, the routine use of GM in these specimens for the diagnosis of invasive aspergillosis is not recommended.

\section{Galactomannan Testing in Solid-Organ Transplant Patients}

SOT recipients are at risk for invasive aspergillosis. The risk is higher among lung transplant recipients who frequently have airway colonization with Aspergillus sp. In addition, the constant exposure of the graft to the environment, the abnormal anatomical and physiological function of the lungs, and chronic immunosuppression make these patients more susceptible to invasive aspergillosis. ${ }^{69}$ 
Table 3 Characteristics of kits currently available for the detection of 1,3 $\beta$-D-glucan

\begin{tabular}{|l|l|l|l|l|l|}
\hline Assay & Manufacturer & Substrate & Cutoff & Optimal cutoff $^{\text {a }}$ & Availability $^{\text {Fungitell(formerly }}$ \\
$\begin{array}{l}\text { Glucatell) } \\
\text { Fssociates of Cape } \\
\text { Cod, Inc., East } \\
\text { Falmouth, MA }\end{array}$ & Limulus polyphemus & $60-80 \mathrm{pg} / \mathrm{mL}$ & $60 \mathrm{pg} / \mathrm{mL}$ & $\begin{array}{l}\text { United States (FDA } \\
\text { approved) and } \\
\text { Europe }\end{array}$ \\
\hline $\begin{array}{l}\text { Fungitec-G test MK } \\
\text { (G-MK) }\end{array}$ & $\begin{array}{l}\text { Seikagaku Corpora- } \\
\text { tion, Tokyo, Japan }\end{array}$ & Tachypleus tridentatus & $20 \mathrm{pg} / \mathrm{mL}$ & $\mathrm{ND}$ & Japan \\
\hline $\begin{array}{l}\text { Beta-glucan test } \\
\text { Wako (Curdlan) }\end{array}$ & $\begin{array}{l}\text { Wako Pure Chemi- } \\
\text { cal Industries, Ltd., } \\
\text { Osaka, Japan }\end{array}$ & Tachypleus tridentatus & $11 \mathrm{pg} / \mathrm{mL}$ & $3-5 \mathrm{pg} / \mathrm{mL}$ & Japan \\
\hline $\begin{array}{l}\text { BGSTAR beta glucan } \\
\text { test Maruha }\end{array}$ & $\begin{array}{l}\text { Maruha Nichiro } \\
\text { Corporation, Tokyo, } \\
\text { Japan }\end{array}$ & Tachypleus tridentatus & $11 \mathrm{pg} / \mathrm{mL}$ & $3-5 \mathrm{pg} / \mathrm{mL}$ & Japan \\
\hline
\end{tabular}

${ }^{a}$ Data from Marchetti et al ${ }^{33}$ and Lamoth et al. ${ }^{34}$

Classic diagnostic criteria for the diagnosis of invasive aspergillosis are difficult to apply in the SOT patients. The clinical presentation may be subtle, including asymptomatic colonization, chronic cough, fever, and malaise. Aspergillus tracheobronchitis may cause airway obstruction, ulcerations, and pseudo-membranes, as well as anastomosis dehiscence in lung transplant recipients. ${ }^{70}$ Furthermore, Aspergillus infection may progress from the upper airway to the lungs and disseminate to extrapulmonary sites, including the CNS. Liver transplant recipients are at increased risk for disseminated disease and CNS involvement compared with other transplant recipients. ${ }^{71}$ Classic radiologic findings are also less frequent in SOT patients. For instance, the halo sign on computed tomographic (CT) scan of the lungs is rarely observed. Most SOT patients with invasive aspergillosis will present with focal consolidation or infiltrates and nodular lesions on chest CT scan. ${ }^{72}$ The clinical usefulness of culture methods is also limited. Airway colonization with Aspergillus spp. within 6 months after lung transplantation could be as high as $46 \%$ despite prolonged antimold prophylaxis. ${ }^{73}$ Similarly, diagnostic performance of non-culture-diagnostic assays such as serum and BAL-GM is variable in this patient population.

Serum GM is less useful as a diagnostic tool for the diagnosis of invasive aspergillosis in SOT recipients. Pfeiffer et al reported an overall sensitivity and specificity of 22 and $84 \%$, respectively, when serum GM was used in SOT patients. $^{22}$ However, test performance may vary depending on the type of organ transplanted. Indeed, higher sensitivity and specificity of serum GM have been reported among lung transplant recipients (77 and $100 \%$, respectively). ${ }^{74}$

Compared with serum, BAL-GM appears to be more useful for the diagnosis of invasive aspergillosis among SOT recipients. The role of BAL-GM has been best studied in lung transplant recipients. ${ }^{75-79}$ The overall sensitivity of BAL-GM ranges from 60 to $90 \%$ and specificity is $>90 \%$ when using a positivity cutoff value $>0.5$. Increasing cutoff to $>1.0$ ODI improves specificity up to $100 \%$ but compromises sensitivity. ${ }^{74,78}$ This is important owing to the high incidence of falsepositive BAL-GM testing in SOT recipients (50\%), particularly lung transplant patients (up to 56\%) likely due to frequent Aspergillus colonization in these patients. ${ }^{78}$

\section{Galactomannan Testing in Other Populations at Risk of Invasive Aspergillosis}

Over the past three decades, the population at risk for invasive aspergillosis has expanded. Indeed, patients from nonclassic settings such as critically ill patients in the ICU and those with chronic pulmonary diseases (COPD), liver cirrhosis, and severe burns are recognized as "new" populations at risk for invasive aspergillosis. ${ }^{85-89}$ Mortality rates of invasive aspergillosis in these patients are as high as in HCT recipients, reaching up to $90 \%{ }^{86,87}$ As in the classic risk groups, early recognition of invasive aspergillosis is critical to improve outcome. Clinical presentation and radiological findings are nonspecific and diagnostic criteria of invasive aspergillosis are poorly defined in these patient populations. Furthermore, EORCT/MSG diagnostic criteria have not been validated in this setting. Similarly, the data to support the use of GM as diagnostic aid in critically ill patients are limited to four studies. $^{83-89}$ One study reported a sensitivity of $54 \%$ and specificity of $81 \%$ among patients admitted to the ICU with COPD exacerbation. ${ }^{87}$ In the same study, using two consecutive positive serum GM results as a surrogate for diagnosis of invasive aspergillosis did impact sensitivity and specificity (42\% and 93.5\%, respectively). ${ }^{87}$ BAL-GM testing appears more appealing to the critical care setting, likely because respiratory samples such as BAL are more accessible for patients receiving mechanical ventilation. Meersseman et al evaluated the performance of BAL-GM for the diagnosis of invasive aspergillosis in 110 critically ill patients. Using a cutoff value of 0.5 ODI, sensitivity and specificity of BAL-GM was 88 and $87 \%$, respectively. In the same study, sensitivity of serum GM was only $42 \%{ }^{89}$ Similarly, Acosta et al evaluated BAL-GM performance in 51 patients admitted to the ICU. Increasing cutoff to $1.0 \mathrm{ODI}$ improved sensitivity and specificity for proven invasive aspergillosis to 100 and $89.4 \%$, respectively. ${ }^{83}$

In summary, serum GM testing is less useful for the diagnosis of invasive aspergillosis in critically ill patients, whereas BAL-GM appears to have an adequate diagnostic value in this patient population. Further studies are needed to determine the utility of BAL-GM as well as the algorithm to diagnose invasive aspergillosis in critically ill patients. 


\section{Current Management Strategies for Invasive Aspergillosis}

Current strategies for the management of invasive aspergillosis include prophylaxis, empiric, preemptive, and targeted therapy. ${ }^{90,91}$ Antifungal prophylaxis involves the administration of an antifungal drug (active against yeasts or yeasts and molds) to a high-risk patient population before the onset of signs/symptoms of infection (e.g., patients who develop neutropenia after receiving chemotherapy). Despite the controversy, most institutions currently use posaconazole or voriconazole prophylaxis in patients at high risk of invasive aspergillosis. Universal antimold prophylaxis decreases the pretest probability of invasive aspergillosis and screening is not advisable in this setting. In a prospective study, Duarte et al reported on the poor performance of serial serum GM testing in hematology patients receiving effective antimold prophylaxis. ${ }^{92}$ In addition, the study showed improved performance of serum GM when the test is used to confirm the diagnosis of invasive aspergillosis (positive predictive value of 89.6\%). These findings suggest that use of mold-active prophylaxis in high-risk patients is shifting the paradigm, by moving the use of serum GM, from screening to confirmatory test. Nevertheless, sequential serum GM screening remains critical for the early detection of invasive aspergillosis in patients in whom azole prophylaxis is not given or not recommended, such as patients receiving vinca-alkaloid agents. $^{93}$

Preemptive therapy is often initiated when suggestive, but nonspecific radiographic signs are present and/or laboratory tests are suggestive of invasive fungal diseases, in the absence of confirmation of invasive fungal disease. Several strategies for preemptive therapy utilizing noninvasive biomarkers together with high-resolution CT scan have been proposed. ${ }^{94-96}$ Sequential serum GM screening is typically used as a preemptive approach for patients with prolonged neutropenia who do not receive mold active prophylaxis. This strategy enables the early detection of invasive aspergillosis and prompts the initiation of antifungal treatment. ${ }^{95,97,98}$ Although preemptive antifungal therapy has been successfully used in the setting of febrile neutropenic patients, no standard recommendations support its use, pending the results of an ongoing randomized strategy study by the EORTC.

Empirical antifungal therapy is used in high-risk neutropenic patients presenting with persistent or recurring fevers despite 4 to 7 days of appropriate antibiotic therapy (when duration of neutropenia is expected to be more than 7 days). In this setting, an antifungal agent is started despite no microbiological or radiological evidence of a fungal infection. ${ }^{91}$

Targeted therapy relies on treating microbiologically and/ or histologically documented invasive fungal disease. This approach is feasible in low-risk patients who are clinically stable. Despite the strategy used, all efforts should be made to document invasive aspergillosis. ${ }^{90,91}$

The use of sequential testing with serum GM as a surrogate marker of clinical response to treatment in patients with invasive aspergillosis has been studied. ${ }^{99-102}$ The correlation between serum GM titers and clinical outcome has been reported in multiple myeloma and acute leukemia patients. These studies showed that the titer of GM tends to decrease with clinical response. Similarly, increasing titers have been associated with poor outcomes. ${ }^{100,102,103}$ Although these findings have potential implications in the management of patient with invasive aspergillosis, this strategy remains under investigation. ${ }^{104}$

\section{Conclusion}

The clinical usefulness of GM and BDG testing, used for the detection of cell-wall antigens of Aspergillus, either as part of a screening approach or as a confirmatory test, depends on the clinicians' awareness of their strengths and weaknesses. Each of these tests (including PCR for the detection of fungal DNA) has its own limitations. Future research should probably focus on combining several of these tests to achieve optimal performance for the diagnosis of invasive aspergillosis and subsequent appropriate and more cost-effective patient management. Meanwhile, novel promising detection techniques are being explored, such as the point-of-care lateral-flow devices.

\section{References}

1 Thompson GR III, Patterson TF. Pulmonary aspergillosis. Semin Respir Crit Care Med 2008;29(2):103-110

2 Marr KA, Carter RA, Crippa F, Wald A, Corey L. Epidemiology and outcome of mould infections in hematopoietic stem cell transplant recipients. Clin Infect Dis 2002;34(7):909-917

3 De Pauw B, Walsh TJ, Donnelly JP, et al; European Organization for Research and Treatment of Cancer/Invasive Fungal Infections Cooperative Group; National Institute of Allergy and Infectious Diseases Mycoses Study Group (EORTC/MSG) Consensus Group. Revised definitions of invasive fungal disease from the European Organization for Research and Treatment of Cancer/Invasive Fungal Infections Cooperative Group and the National Institute of Allergy and Infectious Diseases Mycoses Study Group (EORTC/ MSG) Consensus Group. Clin Infect Dis 2008;46(12):1813-1821

4 Meersseman W, Lagrou K, Maertens J, Van Wijngaerden E. Invasive aspergillosis in the intensive care unit. Clin Infect Dis 2007;45(2):205-216

5 von Eiff M, Roos N, Schulten R, Hesse M, Zühlsdorf M, van de Loo J. Pulmonary aspergillosis: early diagnosis improves survival. Respiration 1995;62(6):341-347

6 Caillot D, Couaillier JF, Bernard A, et al. Increasing volume and changing characteristics of invasive pulmonary aspergillosis on sequential thoracic computed tomography scans in patients with neutropenia. J Clin Oncol 2001;19(1):253-259

7 Hope WW, Walsh TJ, Denning DW. Laboratory diagnosis of invasive aspergillosis. Lancet Infect Dis 2005;5(10):609-622

8 Rinaldi MG. Problems in the diagnosis of invasive fungal diseases. Rev Infect Dis 1991;13(3):493-495

9 Boudewijns M, Verweij PE, Melchers WJ. Molecular diagnosis of invasive aspergillosis: the long and winding road. Future Microbiol 2006;1(3):283-293

10 Mennink-Kersten MA, Verweij PE. Non-culture-based diagnostics for opportunistic fungi. Infect Dis Clin North Am 2006;20(3): 711-727, viii

11 Ascioglu S, Rex JH, de Pauw B, et al; Invasive Fungal Infections Cooperative Group of the European Organization for Research and Treatment of Cancer; Mycoses Study Group of the National 
Institute of Allergy and Infectious Diseases. Defining opportunistic invasive fungal infections in immunocompromised patients with cancer and hematopoietic stem cell transplants: an international consensus. Clin Infect Dis 2002;34(1):7-14

12 Guinea J, Bouza E. Current challenges in the microbiological diagnosis of invasive aspergillosis. Mycopathologia 2014; 178(5-6):403-416

13 Morton CO, Loeffler J, De Luca A, et al. Dynamics of extracellular release of Aspergillus fumigatus DNA and galactomannan during growth in blood and serum. J Med Microbiol 2010;59(Pt 4): 408-413

14 Hope WW, Kruhlak MJ, Lyman CA, et al. Pathogenesis of Aspergillus fumigatus and the kinetics of galactomannan in an in vitro model of early invasive pulmonary aspergillosis: implications for antifungal therapy. J Infect Dis 2007;195(3):455-466

15 Chamilos G, Luna M, Lewis RE, et al. Invasive fungal infections in patients with hematologic malignancies in a tertiary care cancer center: an autopsy study over a 15-year period (1989-2003). Haematologica 2006;91(7):986-989

16 Lewis RE, Kontoyiannis DP. Invasive aspergillosis in glucocorticoid-treated patients. Med Mycol 2009;47(Suppl 1):S271-S281

17 Barton RC. Laboratory diagnosis of invasive aspergillosis: from diagnosis to prediction of outcome. Scientifica (Cairo) 2013; 2013:459405

18 Galactomannan - Food and Drug Administration - http://www. accessdata.fda.gov/cdrh_docs/pdf9/K093678.pdf2011. Accessed on January 26, 2013

19 Serum Galactomannan- Food and Drug Administration http://www. accessdata.fda.gov/cdrh_docs/pdf6/K060641.pdf2006. Accessed on January 26, 2013

20 Galactomannan - Food and Drug Administration - Regulatory Information. http://www.fda.gov/downloads/Drugs/GuidanceComplianceRegulatoryInformation/Guidances/UCM420248.pdf2015

21 Zou M, Tang L, Zhao S, et al. Systematic review and meta-analysis of detecting galactomannan in bronchoalveolar lavage fluid for diagnosing invasive aspergillosis. PLoS ONE 2012;7(8):e43347

22 Pfeiffer CD, Fine JP, Safdar N. Diagnosis of invasive aspergillosis using a galactomannan assay: a meta-analysis. Clin Infect Dis 2006;42(10):1417-1427

23 Horn DL, Freifeld AG, Schuster MG, Azie NE, Franks B, Kauffman CA. Treatment and outcomes of invasive fusariosis: review of 65 cases from the PATH Alliance( $\left({ }^{\circledR}\right)$ registry. Mycoses 2014;57(11): 652-658

24 Vergidis P, Walker RC, Kaul DR, et al. False-positive Aspergillus galactomannan assay in solid organ transplant recipients with histoplasmosis. Transpl Infect Dis 2012;14(2):213-217

25 Maertens J.A., Personal Communication, February 2015

26 Tortorano AM, Esposto MC, Prigitano A, et al. Cross-reactivity of Fusarium spp. in the Aspergillusgalactomannan enzyme-linked immunosorbent assay. J Clin Microbiol 2012;50(3):1051-1053

27 Walsh TJ, Anaissie EJ, Denning DW, et al; Infectious Diseases Society of America. Treatment of aspergillosis: clinical practice guidelines of the Infectious Diseases Society of America. Clin Infect Dis 2008;46(3):327-360

28 Mori Y, Nagasaki Y, Kamezaki K, et al. High incidence of falsepositive Aspergillus galactomannan test in multiple myeloma. Am J Hematol 2010;85(6):449-451

29 Odabasi Z, Mattiuzzi G, Estey E, et al. Beta-D-glucan as a diagnostic adjunct for invasive fungal infections: validation, cutoff development, and performance in patients with acute myelogenous leukemia and myelodysplastic syndrome. Clin Infect Dis 2004; 39(2):199-205

30 Iwanaga S, Miyata T, Tokunaga F, Muta T. Molecular mechanism of hemolymph clotting system in Limulus. Thromb Res 1992;68(1): $1-32$

31 Karageorgopoulos DE, Vouloumanou EK, Ntziora F, Michalopoulos A, Rafailidis PI, Falagas ME. $\beta$-D-glucan assay for the diagnosis of invasive fungal infections: a meta-analysis. Clin Infect Dis 2011;52(6):750-770

32 Marty FM, Koo S. Role of (1->3)-beta-D-glucan in the diagnosis of invasive aspergillosis. Med Mycol 2009;47(Suppl 1): S233-S240

33 Marchetti O, Lamoth F, Mikulska M, Viscoli C, Verweij P, Bretagne $\mathrm{S}$; European Conference on Infections in Leukemia (ECIL) Laboratory Working Groups. ECIL recommendations for the use of biological markers for the diagnosis of invasive fungal diseases in leukemic patients and hematopoietic SCT recipients. Bone Marrow Transplant 2012;47(6):846-854

34 Lamoth F, Cruciani M, Mengoli C, et al; Third European Conference on Infections in Leukemia (ECIL-3). $\beta$-Glucan antigenemia assay for the diagnosis of invasive fungal infections in patients with hematological malignancies: a systematic review and metaanalysis of cohort studies from the Third European Conference on Infections in Leukemia (ECIL-3). Clin Infect Dis 2012;54(5): 633-643

35 Mengoli C, Cruciani M, Barnes RA, Loeffler J, Donnelly JP. Use of PCR for diagnosis of invasive aspergillosis: systematic review and meta-analysis. Lancet Infect Dis 2009;9(2):89-96

36 Kourkoumpetis TK, Fuchs BB, Coleman JJ, Desalermos A, Mylonakis E. Polymerase chain reaction-based assays for the diagnosis of invasive fungal infections. Clin Infect Dis 2012;54(9): 1322-1331

37 Bašková L, Buchta V. Laboratory diagnostics of invasive fungal infections: an overview with emphasis on molecular approach. Folia Microbiol (Praha) 2012;57(5):421-430

38 Wang Y, Chen L, Liu X, et al. Detection of Aspergillus fumigatus pulmonary fungal infections in mice with $(99 \mathrm{~m})$ Tc-labeled MORF oligomers targeting ribosomal RNA. Nucl Med Biol 2013;40(1): 89-96

39 Cramer RA Jr, Gamcsik MP, Brooking RM, et al. Disruption of a nonribosomal peptide synthetase in Aspergillus fumigatus eliminates gliotoxin production. Eukaryot Cell 2006;5(6): 972-980

40 Pinto LJ, Moore MM. Screening method to identify inhibitors of siderophore biosynthesis in the opportunistic fungal pathogen, Aspergillus fumigatus. Lett Appl Microbiol 2009;49(1):8-13

41 Thornton CR. Development of an immunochromatographic lateral-flow device for rapid serodiagnosis of invasive aspergillosis. Clin Vaccine Immunol 2008;15(7):1095-1105

42 Hoenigl M, Koidl C, Duettmann W, et al. Bronchoalveolar lavage lateral-flow device test for invasive pulmonary aspergillosis diagnosis in haematological malignancy and solid organ transplant patients. J Infect 2012;65(6):588-591

43 Thornton C, Johnson G, Agrawal S. Detection of invasive pulmonary aspergillosis in haematological malignancy patients by using lateral-flow technology. J Vis Exp 2012;(61):

44 Hoenigl M, Prattes J, Spiess B, et al. Performance of galactomannan, beta-d-glucan, Aspergillus lateral-flow device, conventional culture, and PCR tests with bronchoalveolar lavage fluid for diagnosis of invasive pulmonary aspergillosis. J Clin Microbiol 2014;52(6):2039-2045

45 Willinger B, Lackner M, Lass-Flörl C, et al. Bronchoalveolar lavage lateral-flow device test for invasive pulmonary aspergillosis in solid organ transplant patients: a semiprospective multicenter study. Transplantation 2014;98(8):898-902

46 Held J, Schmidt T, Thornton CR, Kotter E, Bertz H. Comparison of a novel Aspergillus lateral-flow device and the Platelia ${ }^{\circledR}$ galactomannan assay for the diagnosis of invasive aspergillosis following haematopoietic stem cell transplantation. Infection 2013;41(6): 1163-1169

47 White PL, Parr C, Thornton C, Barnes RA. Evaluation of real-time PCR, galactomannan enzyme-linked immunosorbent assay (ELISA), and a novel lateral-flow device for diagnosis of invasive aspergillosis. J Clin Microbiol 2013;51(5):1510-1516 
48 Maertens JA, Klont R, Masson C, et al. Optimization of the cutoff value for the Aspergillus double-sandwich enzyme immunoassay. Clin Infect Dis 2007;44(10):1329-1336

49 Leeflang MM, Debets-Ossenkopp YJ, Visser CE, et al. Galactomannan detection for invasive aspergillosis in immunocompromized patients. Cochrane Database Syst Rev 2008;(4): CD007394

50 Maertens J, Verhaegen J, Lagrou K, Van Eldere J, Boogaerts M. Screening for circulating galactomannan as a noninvasive diagnostic tool for invasive aspergillosis in prolonged neutropenic patients and stem cell transplantation recipients: a prospective validation. Blood 2001;97(6):1604-1610

51 Sulahian A, Boutboul F, Ribaud P, Leblanc T, Lacroix C, Derouin F. Value of antigen detection using an enzyme immunoassay in the diagnosis and prediction of invasive aspergillosis in two adult and pediatric hematology units during a 4-year prospective study. Cancer 2001;91(2):311-318

52 Maertens J, Van Eldere J, Verhaegen J, Verbeken E, Verschakelen J, Boogaerts $M$. Use of circulating galactomannan screening for early diagnosis of invasive aspergillosis in allogeneic stem cell transplant recipients. J Infect Dis 2002;186(9):1297-1306

53 Klont RR, Mennink-Kersten MA, Verweij PE. Utility of Aspergillus antigen detection in specimens other than serum specimens. Clin Infect Dis 2004;39(10):1467-1474

54 Guo YL, Chen YQ, Wang K, Qin SM, Wu C, Kong JL. Accuracy of BAL galactomannan in diagnosing invasive aspergillosis: a bivariate metaanalysis and systematic review. Chest 2010;138(4):817-824

55 Hage CA, Reynolds JM, Durkin M, Wheat LJ, Knox KS. Plasmalyte as a cause of false-positive results for Aspergillus galactomannan in bronchoalveolar lavage fluid. J Clin Microbiol 2007;45(2): 676-677

56 Racil Z, Kocmanova I, Toskova M, et al. Galactomannan detection in bronchoalveolar lavage fluid for the diagnosis of invasive aspergillosis in patients with hematological diseases-the role of factors affecting assay performance. Int J Infect Dis 2011;15(12): e874-e881

57 Verdaguer V, Walsh TJ, Hope W, Cortez KJ. Galactomannan antigen detection in the diagnosis of invasive aspergillosis. Expert Rev Mol Diagn 2007;7(1):21-32

58 Penack O, Rempf P, Graf B, Blau IW, Thiel E. Aspergillus galactomannan testing in patients with long-term neutropenia: implications for clinical management. Ann Oncol 2008;19(5):984-989

59 Bergeron A, Belle A, Sulahian A, et al. Contribution of galactomannan antigen detection in BAL to the diagnosis of invasive pulmonary aspergillosis in patients with hematologic malignancies. Chest 2010;137(2):410-415

60 Becker MJ, Lugtenburg EJ, Cornelissen JJ, Van Der Schee C, Hoogsteden HC, De Marie S. Galactomannan detection in computerized tomography-based broncho-alveolar lavage fluid and serum in haematological patients at risk for invasive pulmonary aspergillosis. Br J Haematol 2003;121(3):448-457

61 Musher B, Fredricks D, Leisenring W, Balajee SA, Smith C, Marr KA. Aspergillus galactomannan enzyme immunoassay and quantitative PCR for diagnosis of invasive aspergillosis with bronchoalveolar lavage fluid. J Clin Microbiol 2004;42(12): 5517-5522

62 Luong ML, Filion C, Labbé AC, et al. Clinical utility and prognostic value of bronchoalveolar lavage galactomannan in patients with hematologic malignancies. Diagn Microbiol Infect Dis 2010; 68(2):132-139

63 Antinori S, Corbellino M, Meroni L, et al. Aspergillus meningitis: a rare clinical manifestation of central nervous system aspergillosis. Case report and review of 92 cases. J Infect 2013;66(3): 218-238

64 Verweij PE, Brinkman K, Kremer HP, Kullberg BJ, Meis JF. Aspergillus meningitis: diagnosis by non-culture-based microbiological methods and management. J Clin Microbiol 1999;37(4): 1186-1189
65 Viscoli C, Machetti M, Gazzola P, et al. Aspergillus galactomannan antigen in the cerebrospinal fluid of bone marrow transplant recipients with probable cerebral aspergillosis. J Clin Microbiol 2002;40(4):1496-1499

66 Duettmann W, Koidl C, Troppan K, et al. Serum and urine galactomannan testing for screening in patients with hematological malignancies. Med Mycol 2014;52(6):647-652

67 Miller-Hjelle MA, Hjelle JT, Jones M, et al. Polycystic kidney disease: an unrecognized emerging infectious disease? Emerg Infect Dis 1997;3(2):113-127

68 Verweij PE, Weemaes CM, Curfs JH, Bretagne S, Meis JF. Failure to detect circulating Aspergillus markers in a patient with chronic granulomatous disease and invasive aspergillosis. J Clin Microbiol 2000;38(10):3900-3901

69 Silveira FP, Husain S. Fungal infections in lung transplant recipients. Curr Opin Pulm Med 2008;14(3):211-218

70 Grossi P, Farina C, Fiocchi R, Dalla Gasperina D; Italian Study Group of Fungal Infections in Thoracic Organ Transplant Recipients. Prevalence and outcome of invasive fungal infections in 1,963 thoracic organ transplant recipients: a multicenter retrospective study. Transplantation 2000;70(1):112-116

71 Gavalda J, Len O, San Juan R, et al; RESITRA (Spanish Network for Research on Infection in Transplantation). Risk factors for invasive aspergillosis in solid-organ transplant recipients: a case-control study. Clin Infect Dis 2005;41(1):52-59

72 Park SY, Lim C, Lee SO, et al. Computed tomography findings in invasive pulmonary aspergillosis in non-neutropenic transplant recipients and neutropenic patients, and their prognostic value. J Infect 2011;63(6):447-456

73 Cahill BC, Hibbs JR, Savik K, et al. Aspergillus airway colonization and invasive disease after lung transplantation. Chest 1997; 112(5):1160-1164

74 Tabarsi P, Soraghi A, Marjani M, et al. Comparison of serum and bronchoalveolar lavage galactomannan in diagnosing invasive aspergillosis in solid-organ transplant recipients. Exp Clin Transplant 2012;10(3):278-281

75 Husain S, Kwak EJ, Obman A, et al. Prospective assessment of Platelia Aspergillus galactomannan antigen for the diagnosis of invasive aspergillosis in lung transplant recipients. Am J Transplant 2004;4(5):796-802

76 Husain S, Paterson DL, Studer SM, et al. Aspergillus galactomannan antigen in the bronchoalveolar lavage fluid for the diagnosis of invasive aspergillosis in lung transplant recipients. Transplantation 2007;83(10):1330-1336

77 Luong ML, Clancy CJ, Vadnerkar A, et al. Comparison of an Aspergillus real-time polymerase chain reaction assay with galactomannan testing of bronchoalvelolar lavage fluid for the diagnosis of invasive pulmonary aspergillosis in lung transplant recipients. Clin Infect Dis 2011;52(10):1218-1226

78 Clancy CJ, Jaber RA, Leather HL, et al. Bronchoalveolar lavage galactomannan in diagnosis of invasive pulmonary aspergillosis among solid-organ transplant recipients. J Clin Microbiol 2007; 45(6):1759-1765

79 Pasqualotto AC, Xavier MO, Sánchez LB, et al. Diagnosis of invasive aspergillosis in lung transplant recipients by detection of galactomannan in the bronchoalveolar lavage fluid. Transplantation 2010;90(3):306-311

80 Cai X, Ni W, Wei C, Cui J. Diagnostic value of the serum galactomannan and $(1,3)-\beta$-D-glucan assays for invasive pulmonary aspergillosis in non-neutropenic patients. Intern Med 2014; 53(21):2433-2437

81 Montagna MT, Caggiano G, Lovero G, et al. Epidemiology of invasive fungal infections in the intensive care unit: results of a multicenter Italian survey (AURORA Project). Infection 2013; 41(3):645-653

82 Koulenti D, Garnacho-Montero J, Blot S. Approach to invasive pulmonary aspergillosis in critically ill patients. Curr Opin Infect Dis 2014;27(2):174-183 
83 Acosta J, Catalan M, del Palacio-Peréz-Medel A, et al. A prospective comparison of galactomannan in bronchoalveolar lavage fluid for the diagnosis of pulmonary invasive aspergillosis in medical patients under intensive care: comparison with the diagnostic performance of galactomannan and of $(1 \rightarrow 3)-\beta-d-$ glucan chromogenic assay in serum samples. Clin Microbiol Infect 2011;17(7):1053-1060

84 Blyth DM, Chung KK, Cancio LC, King BT, Murray CK. Clinical utility of fungal screening assays in adults with severe burns. Burns 2013;39(3):413-419

85 Guinea J, Torres-Narbona M, Gijón P, et al. Pulmonary aspergillosis in patients with chronic obstructive pulmonary disease: incidence, risk factors, and outcome. Clin Microbiol Infect 2010;16(7):870-877

86 Fukuda T, Boeckh M, Carter RA, et al. Risks and outcomes of invasive fungal infections in recipients of allogeneic hematopoietic stem cell transplants after nonmyeloablative conditioning. Blood 2003;102(3):827-833

87 Meersseman W, Vandecasteele SJ, Wilmer A, Verbeken E, Peetermans WE, Van Wijngaerden E. Invasive aspergillosis in critically ill patients without malignancy. Am J Respir Crit Care Med 2004; 170(6):621-625

88 He H, Ding L, Li F, Zhan Q. Clinical features of invasive bronchialpulmonary aspergillosis in critically ill patients with chronic obstructive respiratory diseases: a prospective study. Crit Care 2011;15(1):R5

89 Meersseman W, Lagrou K, Maertens J, et al. Galactomannan in bronchoalveolar lavage fluid: a tool for diagnosing aspergillosis in intensive care unit patients. Am J Respir Crit Care Med 2008; 177(1):27-34

90 Ruhnke M, Böhme A, Buchheidt D, et al; Infectious Diseases Working Party in Haematology and Oncology of the German Society for Haematology and Oncology. Diagnosis of invasive fungal infections in hematology and oncology-guidelines from the Infectious Diseases Working Party in Haematology and Oncology of the German Society for Haematology and Oncology (AGIHO). Ann Oncol 2012;23(4):823-833

91 Freifeld AG, Bow EJ, Sepkowitz KA, et al; Infectious Diseases Society of America. Clinical practice guideline for the use of antimicrobial agents in neutropenic patients with cancer: 2010 update by the Infectious Diseases Society of America. Clin Infect Dis 2011;52(4):e56-e93

92 Duarte RF, Sánchez-Ortega I, Cuesta I, et al. Serum galactomannan-based early detection of invasive aspergillosis in hematology patients receiving effective antimold prophylaxis. Clin Infect Dis 2014;59(12):1696-1702
93 Eiden C, Palenzuela G, Hillaire-Buys D, et al. Posaconazoleincreased vincristine neurotoxicity in a child: a case report. J Pediatr Hematol Oncol 2009;31(4):292-295

94 de Pauw BE, Viscoli C. Managing invasive fungal infections: relying on clinical instincts or on a rational navigation system? J Antimicrob Chemother 2011;66(Suppl 1):i55-i58

95 Maertens J, Theunissen K, Verhoef G, et al. Galactomannan and computed tomography-based preemptive antifungal therapy in neutropenic patients at high risk for invasive fungal infection: a prospective feasibility study. Clin Infect Dis 2005;41(9): $1242-1250$

96 Morrissey CO, Bardy PG, Slavin MA, et al. Diagnostic and therapeutic approach to persistent or recurrent fevers of unknown origin in adult stem cell transplantation and haematological malignancy. Intern Med J 2008;38(6b):477-495

97 Tan BH, Low JG, Chlebicka NL, et al. Galactomannan-guided preemptive vs. empirical antifungals in the persistently febrile neutropenic patient: a prospective randomized study. Int J Infect Dis 2011;15(5):e350-e356

98 Cordonnier C, Pautas C, Maury S, et al. Empirical versus preemptive antifungal therapy for high-risk, febrile, neutropenic patients: a randomized, controlled trial. Clin Infect Dis 2009; 48(8):1042-1051

99 Miceli MH, Grazziutti ML, Woods G, et al. Strong correlation between serum Aspergillus galactomannan index and outcome of aspergillosis in patients with hematological cancer: clinical and research implications. Clin Infect Dis 2008;46(9):1412-1422

100 Park SH, Choi SM, Lee DG, et al. Serum galactomannan strongly correlates with outcome of invasive aspergillosis in acute leukaemia patients. Mycoses 2011;54(6):523-530

101 Maertens J, Buvé K, Theunissen K, et al. Galactomannan serves as a surrogate endpoint for outcome of pulmonary invasive aspergillosis in neutropenic hematology patients. Cancer 2009;115(2):355-362

102 Boutboul F, Alberti C, Leblanc T, et al. Invasive aspergillosis in allogeneic stem cell transplant recipients: increasing antigenemia is associated with progressive disease. Clin Infect Dis 2002; 34(7):939-943

103 Woods G, Miceli MH, Grazziutti ML, Zhao W, Barlogie B, Anaissie E. Serum Aspergillus galactomannan antigen values strongly correlate with outcome of invasive aspergillosis: a study of 56 patients with hematologic cancer. Cancer 2007;110(4):830-834

104 Segal BH, Herbrecht R, Stevens DA, et al. Defining responses to therapy and study outcomes in clinical trials of invasive fungal diseases: Mycoses Study Group and European Organization for Research and Treatment of Cancer consensus criteria. Clin Infect Dis 2008;47(5):674-683 